\title{
Acil Servise Başvuran Bireylerde Düşme Riski ve Etkileyen Faktörlerin İncelenmesi
}

\section{Risk of Falling and its Affecting Factors Among Emergency Room Patients}

\author{
(Araştırma) \\ Öznur ERDEM*, Selma ATAY**
}

\begin{abstract}
öz
Amaç: $\mathrm{Bu}$ araştırma, acil servise başvuran bireylerde düşme riski ve etkileyen faktörlerin belirlenmesi amacıyla yapılmıștır.

Gereç ve Yöntem: Araştırma tanımlayıcı nitelikte tasarlanmış olup bir acil servise başvuran 1000 birey ile yürütülmüștür. Verilerin toplanmasında, bireylerin sosyo-demografik özelliklerine yönelik bilgi formu ve acil servis hastalarında kullanılan "KINDER 1" düşme değerlendirme aracı kullanılmıştır. Veriler sayı, yüzde ki-kare analizi ile değerlendirilmiştir.

Bulgular: Araştırmaya katılan bireylerin \%24.5'inin 65 yaş üstünde olduğu, \%49.1'inin erkek, \%55.9'unun kronik hastalığa sahip olduğu bulunmuştur. Bireylerin \%65.3'ünün yüksek düşme riski taşıdığı saptanmıștır. Düşme riski ile yaș, cinsiyet, kronik hastalığa sahip olma, görme ișitme problemi, düșme öyküsü, sürekli ilaç kullanımı, bilinç durumu arasında istatistiksel olarak anlamlı bir fark olduğu bulunmuştur.

Sonuç: Acil servise başvuran bireylerin düşme risklerinin yüksek olduğu bulunmuştur. Elde edilen sonuçlar doğrultusunda; acil serviste bulunan bireylerin düşme risk değerlendirmesinin acil servise spesifik değerlendirme araçları ile yapılması önerilebilir.
\end{abstract}

Anahtar Kelimeler: Acil servis, düşme riski, güvenlik

\section{ABSTRACT}

Aim: This study was conducted to determine the risk of falling and its affecting factors among emergency room (ER) patients.

Material and Methods: This descriptive study was conducted with 1000 patients who presented at ER. The data was collected by using a questionnaire and the KINDER 1 Fall Assessment Tool designed for ER patients. The data were analyzed by using number, percentage and chisquare test.

\footnotetext{
*Çanakkale On Sekiz Mart Üniversitesi Sağlık Bilimleri Enstitüsü, Hemşirelik, Çanakkale, Türkiye, E-mail: erdemoznur@hotmail.com, Tel: 053549038 82, ORCID: https://orcid.org/0000-0002-5858-9933

**Çanakkale On Sekiz Mart Üniversitesi Sağlık Yüksekokulu Hemşirelik Bölümü, Çanakkale, Türkiye, E-mail: selmaatay@gmail.com Tel: 053524051 94, ORCID: https://orcid.org/ 0000-0002-2068-1099 Geliş Tarihi: 29 Ocak 2018, Kabul Tarihi:2 Haziran 2018 25-28 Nisan 2018 tarihinde Belek-Antalya'da yapılan 12. Uluslararası Sağlıkta Kalite, Akreditasyon ve Hasta Güvenliği Kongresi, 2018'de sözel bildiri olarak sunulmuştur.

Atıf/Citatian: Erdem Ö., Atay S. Acil Servise Başvuran Bireylerde Düşme Riski ve Etkileyen Faktörlerin Incelenmesi. Hacettepe Üniversitesi Hemşirelik Fakültesi Dergisi 2018; 5(2)... https://doi.org/
} 
Results: It was found that $24.5 \%$ of the participants were over 65 years old, $49.1 \%$ were male and $55.9 \%$ had chronic disease. $65.3 \%$ of the participants were found to have a high risk of falling. A statistically significant difference between the risk of falling and age, gender, having chronic illness, visual/hearing problem, history of falling, continuous drug use, state of consciousness was found.

Conclusion: It was found that patients who presented at ER had a high risk of falling. According to the study results, it could be advised to assess the falling risk of ER patients with assessment tools specific to ER.

Key Words: Emergency room, risk offalling, safety

\section{GiRiş}

Hasta düşmeleri, hasta mortalite ve morbidite oranında artışın yanı sıra maliyette artışa da sebep olduğu için önemli bir konudur ${ }^{1-3}$. Düşmelere bağlı gelişen ciddi yaralanmaların büyük kısmını kalça ve pelvis kırıklarının oluşturduğu, daha sonrasında ise üst ve alt ekstremite kırık ve çıkıkları ile kafa ve omurga yaralanmalarının geldiği belirtilmektedir ${ }^{1,4-6}$. Sağlık Kuruluşları Akreditasyonu Ortak Komisyonu (JCI), raporunda; ABD' de hastanelerde her yıl yüz binlerce hastanın düştüğünü, bunlarında \% 30-50 oranında yaralanma ile sonuçlandığını, yaralanan bireylere ilave tedavilerin gerektiğini, bununda hastanede kalış süresini uzattığını, bir düşme sonrası yaralanma maliyetinin de kişi başı yaklaşık 14.000 dolar olduğunu belirtilmiştir7. Ülkemizde yapılan bir çalışmada ise, hastanelerde gerçekleşen ciddi düşmelerin neden olduğu maliyet artışının 8726,94 TL olduğu, ayrıca düşmelerin hastane yatış süresini 14,61 gün artırdığı belirtilmektedir ${ }^{2}$. Dünyada ve ülkemizde kliniklerde hasta düşmelerinin değerlendirildiği çalışmalar mevcuttur ${ }^{8-15}$. Ancak acil serviste bulunan bireylerde düşme değerlendirilmesine ilişkin sınırlı sayıda çalışmaya ulaşılmıştır ${ }^{16-18}$. Bir acil serviste iki yıllık dönemde meydana gelen 57 düşme vakasının retrospektif incelendiği çalışmada, acil servislerde düşme değerlendirmesinde yatan hastalarda kullanılan değerlendirme aracının duyarlılı̆̆ını \%37.5 bulmuşlar ve çalışmanın sonucunda acil servisteki bireylerin düşme risklerinin değerlendirilmesinde kliniklerde kullanılan değerlendirme araçlarının uygun olmadığını belirtmişlerdir ${ }^{19}$. Düşmeye bağlı yaralanmaların bireylere ve kurumlara yükünü azaltmak için acil servise gelen bireylerin düşme değerlendirmesi yapılmasının büyük önem taşıdığı belirtilmektedir ${ }^{3}$. Acil servislerde 7 gün, 24 saat kesintisiz sağlık hizmeti sunulmaktadır. Acil servisler belirsiz ve beklenmeyen hızlı olayların olduğu kalabalık, hasta düşmeleri için büyük potansiyel taşıyan ortamlardır16-17. Tanrıkulu ve Sarı (2017) çalışmalarında, acil servise başvuran hastaların \%30,3’ünün düşme riskinin yüksek olduğunu saptamışlardır. Özellikle hastaların bireysel özellikleri, kronik hastalık durumu, acil serviste bulunduğu birim, acil servise başvuru nedeninin düşme riskini etkilediğini belirtmişlerdir ${ }^{18}$.

Düşmeye bağlı yaralanmaların bireylere ve kurumlara yükünü azaltmak için acil servise gelen bireylerin düşme değerlendirmesi yapılması büyük önem taşımaktadır³. $\mathrm{Bu}$ araştırma, acil servise başvuran bireylerin düşme riskinin değerlendirilmesinde acil servise spesifik düşme değerlendirme aracı kullanılarak yapılmıştır. 


\section{GEREÇ ve YÖNTEM}

\section{Araştırmanın Türü}

$\mathrm{Bu}$ araştırma, acil servise başvuran bireylerin düşme riskinin değerlendirilmesi ve etkileyen faktörlerin incelenmesi amacıyla planlanmış tanımlayıcı bir çalışmadır.

\section{Araştırmanın Evren ve Örneklemi}

Araştırmanın evrenini; bir devlet hastanesinin acil servisine başvuran, araştırmaya katılmayı kabul eden, 18 yaş ve üzeri hastalar oluşturmuştur. Araştırmanın örneklem hesaplanmasında güç analizi kullanılmıştır. Güç analizi ile belirlenen, 1000 birey örnekleme dahil edilmiştir.

\section{Veri Toplama Araçları}

Veri toplama aracı olarak araştırmacılar tarafından literatür doğrultusunda oluşturulan hasta bilgi formu ve acil servise spesifik düşme risk tanılama aracı olan KINDER 1 düşme risk değerlendirme aracı kullanılmıştır. Hasta bilgi formu iki bölümden oluşmaktadır. Birinci bölüm; hastanın yaş, cinsiyet, eğitim ve medeni durumu gibi demografik özelliklerini, ikinci bölüm ise; hastada düşmeye sebep olabilecek kronik hastalık durumu, görme/işitme problemi, acile geliş sebebi, sürekli kullandığ 1 ilaçlar, bilinç durumu, düşme öyküsü ve acil serviste bulunduğu birimi içeren sorulardan oluşmuştur.

\section{KINDER 1 Düşme Risk Değerlendirme Aracı}

2010 yılında Alexander ve arkadaşları tarafından geliştirilen KINDER 1 düşme risk değerlendirme aracı, acil servise özgü olup, hastaların düşme riskini belirlemektedir. $\mathrm{Bu}$ araç; hareket yeterliliği, mental durumda değişiklik, 70 yaş üzeri olma ve acil servise düşme nedeni ile başvurma durumlarının sorgulandığı 4 maddeden ve değerlendirmeyi yapan hemşirenin hastaya ilişkin gözlemlerini ifade ettiği kısımdan oluşmaktadır. Değerlendirme aracında sorulara cevaplar hemşire tarafından hasta değerlendirildikten sonra evet/hayır şeklinde verilmektedir. Araçtaki sorulardan birinin "evet" olarak değerlendirilmesi hastanın "yüksek düşme riski” taşıdığını göstermektedir. Aracın Türkçeye uyarlanması Erdem (2018) tarafından yapılmıştır19. Kapsam geçerliği için maddelerin uygunluğu konusunda uzman görüşleri arasındaki uyumun değerlendirilmesi amacıyla Kendall's W iyi uyuşum analizi yapıldığı, uzman görüşleri arasında anlamlı bir fark olmadığı belirtilmiştir (Kendall’s $W=.243, p=.121$ ). Araçta veriler katogorik olduğu için bağımsız gözlemciler arasında uyuma bakmak için kappa testi kullanıldığı, iki gözlemcinin sonuçları arasında mükemmel tutarlılığın olduğu vurgulanmıştır $(\mathrm{K}=1.00, \mathrm{p}<.001)^{19}$.

\section{Verilerin Toplanması}

Araştırmanın uygulaması için, ilgili kurumdan yazılı izin ve çalışmaya katılan hastalardan aydınlatılmış onam alındıktan sonra veriler Aralık 2016 - Mayıs 2017 
tarihleri arasında toplanmıştır. Veriler, araştırmacı tarafından yüz yüze görüşme yöntemiyle toplanmıştır. Bir birey ile görüşme ortalama 10-15 dakika sürmüştür.

\section{Araştırmanın Sınırlılıkları}

KINDER 1 Düşme değerlendirme aracının seçicilik ve duyarlılığına bakılmamış olması araştırmanın bir sınırlılığıdır.

\section{Araştırmanın Etik Yönü}

Araştırmanın yapılması için araştırmanın yapıldığı kurumun etik kurulundan (Karar No: 2016-21) resmi izin ve araştırmaya katılmayı kabul eden bireylerden yazılı izin alınmıştır.

\section{Verilerin Analizi}

Araştırmadan elde edilen verilerin değerlendirilmesi bilgisayar ortamında Statistical Package For Social Sciences (SPSS) for Windows 20.00 paket programı kullanılarak yapılmıştır (SPSS 2011).Veriler sayı, yüzde ki-kare analizi ile değerlendirilmiştir.

\section{BULGULAR}

Çalışmaya dahil edilen bireylerin \%46.1'inin 18-44 yaş aralığında, \%50.9’unun kadın, \% 45.1'i ilkokul, \% 69.9'unun evli olduğu belirlenmiştir. Çalışmaya dahil edilen bireylerin \%55.9'unun kronik hastalığa sahip olduğu, bunlarında \%53.8'inin ise iki ve üzerinde kronik hastalığa sahip olduğu, \%11.2'si görme/işitme problemi olduğu bulunmuştur. Çalışmaya dahil edilen bireylerin bilinç durumunda \%80.2'sinin uyanık ve oryante olduğu saptanmıştır. Ayrıca bireylerin \%25.9’unun düşme öyküsü mevcuttur.

Çalışmaya dahil edilen bireylerin KINDER 1 Düşme Değerlendirme aracına göre düşme riski sonuçları Tablo 1'de verilmiştir. Çalışmaya dahil olan bireylerin \%65.3'ünün yüksek düşme riski taşıdığ 1 \% 34.7 'sinin ise düşme riski bulunmadığ 1 saptanmıştır.

Bireylerin demografik özellikleri ve düşmeye sebep olabilecek değişkenler ile düşme değerlendirme sonuçlarının karşılaştırılması Tablo 2'de verilmiştir. 65 yaş ve üstü bireylerin \%95.5'inin yüksek düşme riski taşıdığı bulunmuştur. Yapılan istatiksel analiz sonucunda yaş grupları arasında anlamlı bir fark olduğu saptanmıştır $\left(\mathrm{x}^{2}=162.28, \mathrm{p}<0.001\right)$. Araştırmaya dahil edilen kadınların \%68.4'ünün, erkeklerin ise \%62.1'inin yüksek düşme riski taşıdığı, bireylerin cinsiyetleri ile düşme riski arasında istatiksel olarak anlamlı bir fark olduğu bulunmuştur $\left(\mathrm{x}^{2}=4.31, \mathrm{p}<0.05\right)$. Çalışmamızda kronik hastalığı olan bireylerin \%77.6'sının yüksek düşme riski taşıdığı saptanmıştır.

Tablo 1. Bireylerin Düşme Risk Değerlendirme Sonuçları

\begin{tabular}{|l|c|c|}
\hline Düşme Riski & Sayı & $\%$ \\
\hline Yüksek Düşme riski var & 653 & 65.3 \\
\hline Yüksek Düşme riski yok & 347 & 34.7 \\
\hline
\end{tabular}


Tablo 2. Bireylerin Demografik Özellikleri ve Düşmeye Sebep Olabilecek Değişkenler ile Düşme Değerlendirme Sonuçlarının Karşılaştırılması

\begin{tabular}{|c|c|c|c|c|c|c|}
\hline \multirow{3}{*}{$\begin{array}{l}\text { Demografik özellikleri } \\
\text { ve düşmeye sebep } \\
\text { olabilecek değişkenler }\end{array}$} & \multicolumn{4}{|c|}{ Yüksek Düşme Riski } & \multirow{2}{*}{ Toplam } & \multirow{3}{*}{$\mathbf{P}$} \\
\hline & \multicolumn{2}{|c|}{ Var } & \multicolumn{2}{|c|}{ Yok } & & \\
\hline & sayı & $\%$ & sayı & $\%$ & sayı & \\
\hline \multicolumn{7}{|l|}{ Yaş } \\
\hline $18-44$ & 220 & 47.7 & 241 & 52.3 & 461 & \multirow{3}{*}{$x^{2}=162.28, p=.001$} \\
\hline $45-64$ & 199 & 67.7 & 95 & 32.3 & 294 & \\
\hline 65 yaş ve üstü & 234 & 95.5 & 11 & 4.5 & 245 & \\
\hline \multicolumn{7}{|l|}{ Cinsiyet } \\
\hline Kadın & 348 & 68.4 & 161 & 31.6 & 509 & \multirow[t]{2}{*}{$\mathrm{x}^{2}=4.31, \mathrm{p}>.001$} \\
\hline Erkek & 305 & 62.1 & 186 & 37.9 & 491 & \\
\hline \multicolumn{7}{|l|}{ Kronik Hastalık } \\
\hline Var & 434 & 77.6 & 125 & 22.4 & 653 & \multirow[t]{2}{*}{$x^{2}=85.1, p<0.001$} \\
\hline Yok & 219 & 49.7 & 222 & 50.3 & 347 & \\
\hline \multicolumn{7}{|l|}{$\begin{array}{l}\text { Tek yada Çoklu kronik } \\
\text { hastalık (559) }\end{array}$} \\
\hline Tek Kronik Hastalık & 180 & 69.8 & 78 & 30.2 & 258 & \multirow[t]{2}{*}{$X^{2}=16.23, p<0.001$} \\
\hline İki ve + Kronik hastalık & 253 & 84.1 & 48 & 15.9 & 301 & \\
\hline \multicolumn{7}{|l|}{ Görme/Işsitme Problemi } \\
\hline Var & 103 & 92.0 & 9 & 8.0 & 112 & \multirow[t]{2}{*}{$X^{2}=39.57, p<0.001$} \\
\hline Yok & 550 & 61.9 & 338 & 38.1 & 888 & \\
\hline \multicolumn{7}{|l|}{ Düşme Öyküsü } \\
\hline Var & 198 & 76.4 & 61 & 23.6 & 259 & \multirow[t]{2}{*}{$x^{2}=19.17, p<0.001$} \\
\hline Yok & 455 & 61.4 & 286 & 38.6 & 741 & \\
\hline \multicolumn{7}{|l|}{ Sürekli kullandığı ilaç } \\
\hline Var & 421 & 78.5 & 115 & 21.5 & 536 & \multirow[t]{2}{*}{$x^{2}=89.43, p<0.001$} \\
\hline Yok & 232 & 50.0 & 232 & 50.0 & 464 & \\
\hline \multicolumn{7}{|l|}{ Bilinç durumu } \\
\hline $\begin{array}{l}\text { Uyanık ve oryante (yer- } \\
\text { zaman-kişi) }\end{array}$ & 459 & 57.2 & 343 & 42.8 & 802 & \\
\hline Oryantasyonu yok & 183 & 100.0 & - & - & 183 & $X^{2}=120.71, p<0.001$ \\
\hline $\begin{array}{l}\text { Aralıklı } \\
\text { konfüzyon(Davranışlar } \\
\text { huzursuz, organizasyon } \\
\text { ve amaçtan yoksundur) }\end{array}$ & 11 & 73.3 & 4 & 26.7 & 15 & \\
\hline
\end{tabular}

${ }^{*}$ ki-kare test 
Kronik hastalık ile düşme riski arasında istatistiksel olarak anlamlı bir fark olduğu saptanmıştır $\left(\mathrm{x}^{2}=85.1, \mathrm{p}<0.001\right)$. Sahip olunan kronik hastalık sayısının tek ya da iki ve üzerinde olması ile düşme riski arasındaki fark istatiksel olarak anlamlı bulunmuştur $\left(\mathrm{x}^{2}=16.23, \mathrm{p}<0.001\right)$. Çalışmaya dahil edilen bireylerin görme/işitme problemi olanların \%92.0'sinin yüksek düşme riski taşıdığı, görme/işitme problemi ile düşme riski arasında istatiksel olarak anlamlı bir fark olduğu saptanmıştır $\left(\mathrm{x}^{2}=39.57, \mathrm{p}<0.001\right)$. Düşme öyküsü olanların \%76.4'ünün yüksek düşme riski taşıdığı, düşme öyküsü ile düşme riski arasında istatiksel olarak anlamlı bir fark olduğu saptanmıştır $\left(\mathrm{x}^{2}=19.17, \mathrm{p}<0.001\right)$. Çalışmaya dahil edilen bireylerden sürekli ilaç kullandığını belirtenlerin \%78.5'inin yüksek düşme riski taşıdığı saptanmıştır. Sürekli ilaç kullanımı ile düşme riski arasında istatiksel olarak anlamlı bir fark olduğu bulunmuştur $\left(\mathrm{x}^{2}=89.43, \mathrm{p}<0.001\right)$. Çalışmaya dahil edilen bireylerden oryantasyonu olmayan bireylerin tamamının yüksek düşme riski taşıdığı, uyanık ve oryante olan bireylerde de bu oranın azımsanmayacak oranda yüksek (\%57.2) olduğu görülmüştür. Bilinç durumu ile düşme riski arasında istatiksel olarak anlamlı bir fark olduğu bulunmuştur $\left(\mathrm{X}^{2}=120.71, \mathrm{p}<0.001\right)$.

\section{TARTIŞMA}

Çalışmaya dahil edilen bireylerin, acil servise spesifik KINDER 1 Düşme Değerlendirme aracına göre düşme riski sonuçlarında, \%65.3’ünün yüksek düşme riski taşıdığg 1 saptanmıştır. Acil servisler, hastaya uygulanacak müdahalelerin aciliyet gerektirmesi yanında hasta ve yakınlarının yüksek stres düzeyine sahip olması, çalışma koşullarının ağır olması, hasta yoğunluğunun fazla olması ve karmaşı teknoloji kullanımı gibi faktörler hasta güvenliğini tehdit etmektedir. Bu tür yerler hasta düşmesi için büyük bir potansiyel teşkil etmektedir. ${ }^{16}$ Tanrıkulu ve Sarı’nın (2017) çalışmalarında acil servise başvuran bireylerin \%30.3'ünün düşme riski yüksek, \%26.1'i orta, \%43.6'sı ise az düşme riskine sahip olduğu bulunmuştur ${ }^{18}$. Townsend ve arkadaşları (2016) çalışmalarında, acil servise başvuran bireylerin \%27'sinin yüksek düşme riski taşıdığını belirtmişlerdir ${ }^{3}$. $\mathrm{Bu}$ sonuçları birleştirdiğimizde düşme acil servislerde de önemli bir problemdir. $\mathrm{Bu}$ nedenle değerlendirilmesinde kullanılan araçların acil servise özel olmasının önemli olduğunu söyleyebiliriz.

Çalışmamızda 65 yaş ve üstü hastaların \%95.5'inin yüksek düşme riski taşıdığ 1 bulunmuştur. Literatürde, yaşın ilerlemesi ile düşme riskinin arttığg belirtilmektedir ${ }^{2,20-21}$. Yaşlı yetişkinler arasında düşme hem ölümcül hem de ölümcül olmayan kasıtsız yaralanmaların başında gelmektedir ${ }^{4,20,22}$. 65 yaş üstü bireylerin her y1l 1/3'ünün düştüğg̈ belirtilmektedir ${ }^{23-24}$. WHO raporuna göre, her y1l 65 yaş ve üzeri bireylerin düşme oranı $\% 28-\% 35$ arasında iken, bu oran 70 yaşından sonra $\% 32-\% 42$ 'ye çıkmaktadır ${ }^{4}$. Çalışma sonuçlarımıza benzer şekilde DeGrauw ve arkadaşları (2016) çalışmalarında, 2006-2011 tarihleri arasında acil servise gelen bireylerin kasıtsız düşme yaralanmalarının 65 yaş üzerindeki bireylerde arttığını belirtmişlerdir ${ }^{22}$. Tanrıkulu ve Sarı̉nın (2017) çalışmalarında acil servise başvuran 65 yaş ve üzeri hastaların \%58.3'ünün yüksek düşme riski taşıdığını belirtmişler ve düşme riskinin yaş ile birlikte doğru orantılı arttığını bulmuşlardır ${ }^{18}$. Barış, İntepeler ve Yeginboy (2016) retrospektif çalışmalarında, kliniklerde toplam 1622 düşme raporu incelenmişler ve sonuçlarda ciddi düşmelerin; \%69.2'sinin 60 yaş ve üzeri hastalarda gerçekleştiğini belirtmişlerdir² . $\mathrm{Bu}$ durum, yaşla birlikte kronik hastalıkların, çoklu ilaç kullanımının artması, görme/ 
işitme problemlerinin artması, denge problemlerinin görülmesi, fiziksel fonksiyonların ve kas gücünün azalmasıyla açıklanabilir.

Araştırmada, düşme riskinin cinsiyete göre farklılıkgösterdiği bulunmuştur. Literatürde cinsiyet ve düşme riski arasındaki ilişkiye ilişkin farklı sonuçlar bulunmaktadır. Bazı çalışmada kadın hastalarda erkeklere göre düşmeye bağlı yaralanma oranı daha yüksek belirtilirken, bazılarında ise erkek hastalarda düşmeye bağlı yaralanma oranı daha yüksek belirtilmektedirr ${ }^{19,25}$. Tanrıkulu ve Sarı'nın (2017) çalışmalarında ise düşme riski ile cinsiyet arasında anlamlı ilişki olmadığına vurgu yapılmıştır ${ }^{18}$. Barış, İntepeler ve Yeginboy (2016) çalışmalarında, ciddi düşme deneyimi yaşayan erkek hastaların sayısı kadın hastaların yaklaşık iki katı olarak belirtilmiştir ${ }^{2}$. Araştırma sonucumuzu destekler şekilde Karataş ve Maral'ın çalışmasında (2001), 65 ve üzeri yaş grubunda kadın cinsiyetinin düşme riskini yaklaşık 4 kat artırıcı risk faktörü olduğu belirtilmiştir ${ }^{26}$.

$\mathrm{Bu}$ araştırmada, kronik hastalığa sahip olma durumu ile düşme riski arasında istatistiksel olarak anlamlı bir fark olduğu saptanmıştır. Tanrıkulu ve Sarı'nın (2017) çalışmalarında da, acil servise başvuran hastaların kronik hastalık ile düşme riski düzeyi arasında istatistiksel olarak anlamlı fark olduğu bulunmuştur ${ }^{18}$. Öz (2016) acil servise düşme ön tanısıyla başvuran 65 yaş üstü bireylerde evde düşme risk faktörlerinin belirlenmesi başlıklı çalışmasında, kronik hastalık varlığının düşme riskini etkilediğini bulmuştur ${ }^{27}$. Bu duruma kronik hastalıkların yaşla birlikte artmasının neden olduğunu söyleyebiliriz.

Araştırmada bireylerin görme/işitme problemi ile düşme riski arasında istatiksel olarak anlamlı bir fark olduğu saptanmıştır. Literatürde bireylerin görme/işitme problemi olmasının düşme riskini artırdığ belirtilmektedir $^{10,28}$. Görme dengenin sağlanmasında önemli olduğu için görmenin bozulması düşme için bir risk faktörüdür ${ }^{29}$. KällstrandEricson ve Hildingh (2009) çalışmalarında, görme kaybının düşme riskini artırdığını belirtmişlerdir ${ }^{30}$. İşitme kaybının, vestibüler bozuklukların, baş dönmesi ve denge kaybının düşme için risk faktörü olduğu belirtilmektedir ${ }^{31}$. İşitme kaybı ve düşme öyküsü arasındaki ilişkinin incelendiği bir çalışmada, 2001- 2004 yılları arasında 4069 yaş arası 2017 katılımcı dahil edilmiş ve çalışma sonucunda işitme kaybında her 10 dB artışın son 1 yılda düşme oranını 1.4 kat arttırdığ 1 belirlenmiştir ${ }^{28}$. Tanrıkulu ve Sarı’nın (2017) çalışmalarında ise, görme problemi olan bireylerin \%70.8'inin yüksek düşme riski taşıdığı bulunmuştur.

Araştırmada düşme öyküsü olan bireylerin \%76.4'ünün yüksek düşme riski taşıdığı bulunmuştur. Düşme tanılama ölçeklerinde daha önce düşme öyküsünün olması düşme açısından risk faktörü olarak değerlendirilmektedir ${ }^{24,32}$. Yapılan çalışmalarda da hastaların düşme hikâyesinin olmasının düşme korkusuna sebep olarak düşme riskini arttırdığını göstermektedir ${ }^{9,35-36}$. Çalışma sonuçlarımıza benzer şekilde Tanrıkulu ve Sarı'nın (2017) acil serviste bulunan hastalarda yaptıkları çalışmada da düşme hikâyesi olan bireylerin \%61,5'inin düşme riski yüksek bulunmuştur ${ }^{18}$.

Araştırmada bireylerin sürekli ilaç kullandığını belirtenlerin \%78.5’inin yüksek düşme riski taşıdığ bulunmuştur. Literatürde ilaç kullanımının düşme için risk oluşturduğu belirtilmektedir ${ }^{7,18,35-37}$. Bu bulgumuzu destekler şekilde Öz'ün (2016) acil servise düşme ön tanısıyla başvuran 65 yaş üstü bireylerde evde düşme risk faktörlerinin belirlenmesi başlıklı çalışmasının sonucunda, sürekli ilaç kullanma ve kullanılan ilaç sayısının 
düşme sayısını etkilediği bulunmuştur ${ }^{27}$. Tanrıkulu ve Sarı́nın (2017) çalışmalarında, düşme açısından riskli ilaç kullanan hastaların \%46'sının yüksek düşme riski taşıdığ 1 belirtilmiştirr ${ }^{18}$. Bu durum sürekli ilaç kullanan bireylerin genellikle kronik hastalığ olan, yaşı bireyler olmasıyla açıklanabilir.

Araştırmaya dahil edilen bireylerden oryantasyonu olmayan bireylerin tamamının yüksek düşme riski taşıdığı, uyanık ve oryante olan bireylerde de bu oranın azımsanmayacak oranda yüksek (\%57.2) olduğu görülmüştür. Literatürde bilinç durumundaki değişiklerin bireylerin düşme riskini artırdığı belirtilmektedir ${ }^{39-40}$ Tanrıkulu ve Sarı'nın (2017) çalışmalarında, acil serviste bulunan oryantasyonu bozuk ya da aralıklı konfüzyonu olan bireylerin \%93,5'inin yüksek düşme riski bulunduğu belirtilmiştir. Berke'nin (2008) nöroşirurji hastalarında yaptığı çalışmasında ise oryantante olmayan bireylerin \%90'ının düșme riski yüksek bulunmuștur ${ }^{9}$. Nogal ve arkadaşlarının (2008) yaptığı çalışmada ise, nörolojik problemi bulunan hastaların düşmelerinde mental durumun etkili olması önemli derecede anlamlı olarak gösterilmektedir ${ }^{39}$. Çalışmamızdaki bu bulgu yapılan diğer çalışma sonuçlarıyla benzerlik göstermektedir. Oryantasyon bozukluğu denge problemine neden olacağ 1 için düşmeyi artırıcı bir risk faktörüdür.

\section{SONUÇ ve ÖNERILER}

Bu araştırmada acil serviste bulunan bireylerin, \%65.3'ünün yüksek düşme riski taşıdığı belirlenmiștir. Bireylerin yaşı, cinsiyeti, kronik hastalık durumu, sürekli kullandığı ilaç olması, düşme öyküsünün varlığı ile düşme riski arasında anlamlı bir fark olduğu saptanmıştır. Araştırma sonuçlarına göre, acil serviste bulunan bireylerin düşme risklerinin belirlenmesinde acil servise spesifik düşme araçlarının kullanılması önerilebilir.

\section{KAYNAKLAR}

1. Dunne TJ, Gaboury I, Ashe MC. Falls in hospital increase length of stay regardless of degree of harm, J Eval Clin Pract, 2014; 20(4):396-400.

2. Baris VK, Intepeler SS, Yeginboy EY. The Cost of Serious Patient Fall-Related Injuries at Hospitals in Turkey: A Matched Case-Control Study. Clin Nurs Res. 2016 Sep 29. pii: 1054773816671521.

3. Townsend AB, Valle-Ortiz M, Sansweet T. A successful ED fall risk program using the KINDER 1 Fall Risk Assessment Tool. J Emerg Nurs. 2016;42(6):492-497.

4. World Health Organization. WHO global report on falls prevention in older age, 2007;1-48. http://www. who.int/ageing/publications/Falls_prevention7March.pdf, Erişimtarihi:05.01.2018. WHO 2007

5. Galbraith GJ, Butler JS, Memon AR, Dolan MA, Harty JA, Cost Analysis of a Falls-prevention Program in an Orthopaedic Setting, Clin Orthop Relat Res. 2011 Dec; 469(12): 3462-3468.

6. Zecevic AA, Chesworth BM, Zaric GS, Huang Q, Salmon A, McAuslan D, Welch R, Brunton D. Estimating the cost of serious injurious falls in a Canadian acute care hospital. Can J Aging. 2012 Jun;31(2):139-47. doi: 10.1017/S0714980812000037. Epub 2012 May 24.

7. The Joint Commission. Preventing falls and fall-related injuries in health care facilities. Sentinel Event Alert. 2015; 55: 3. http://www.jointcommission.org/sea_issue_55/. Erişim tarihi: 01.01.2018.

8. Savcı C, Kaya H, Acaroğlu R, Kaya N, Bilir A, Kahraman H, Gökerler N. Nöroloji ve nöroşirurji kliniklerinde hastaların düşme riski ve alınan önlemlerin belirlenmesi. Maltepe Üniversitesi Hemşirelik Bilim ve Sanatı Dergisi. 2009; 2(3):19-25. 
9. Berke D. Nöroşirurji hastalarında düşme risk derecesinin belirlenmesi. Marmara Üniversitesi, Sağlık Bilimleri Enstitüsü Yüksek Lisans Tezi, İstanbul, 2008.

10. Mollaoğlu M, Fertelli T, Tuncay FÖ. Dahili kliniklerde yatan bireylerin düşme riski ve alınan önlemlerin incelenmesi. TAF Preventive Medicine Bulletin. 2013; 12(1):27-34.

11. Tzeng HM, Yin CY. Most frequently observed risk factors for adult inpatient injurious falls in hospitals. Clinical Nurse Specialist. 2013; 27:314-322.

12. Schwendimann R, Buhler H, De Geest S, Milisen K. Characteristics of hospital inpatient falls across clinical departments, Gerontology, 2008;54(6):342-348

13. Chelly JE, Canroy L, Miller G, Elliot MN ve ark. Risk factors and injury associated with falls in elderly hospitalized patients in a community hospital, Patient Saf, 2008;4(3):178-183

14. Zecevic AA, Chesworth BM, Zaric GS, Huang Q, Salmon A, McAuslan D, Welch R, Brunton D. Estimating the cost of serious injurious falls in a Canadian acute care hospital. Can J Aging. 2012 Jun;31(2):139-47. doi: 10.1017/S0714980812000037.

15. Haines TP, Waldron NG. Translation of falls prevention knowledge into action in hospitals: what should be translated and how should it be done?, J Safety Res, 2011;42(6):431-424.

16. Alexander D, Kinsley TL, Waszinski C. Journey to a safe environmental: Fall prevention in an emergency department at a level 1 trauma center. Journal of Emergency Nursing 2013; 39(4):346-352.

17. Potter R. Falls in the emergency department. Journal of Emergency Nursing. 2015; 41:466-468.

18. Tanrikulu F, Sari D. Determining patients' risk of falling in the emergency department. International Journal of Caring Sciences. 2017; 10(2): 907-914.

19. Erdem Ö (2018). Acil Servise Gelen Hastalarda Düşme Riski Ve Etkileyen Faktörlerin İncelenmesi, Yüksek Lisans Tezi, Çannakkale Onsekiz Mart Üniversitesi,Sağlık Bilimleri Enstitüsü, Çanakkale.

20. Terrell KM, Weaver CS, Giles BK, Ross MJ. ED patient falls and resulting injuries. J Emerg Nurs. 2009 Apr;35(2):89-92. doi: 10.1016/j.jen.2008.01.004. Epub 2008 Jul 10.

21. Weigand JV, Gerson LW. Preventive care in the emergency department: Should emergency departments institute a falls prevention program for elder patients? A systematic review. Acad Emerg Med. 2001; 8:823-826.

22. DeGrauw X, Annest J L, Stevens J A, Xu L, Coronado, V. Unintentional injuries treated in hospital emergency departments among persons aged 65 years and older, United States, 2006-2011. Journal of Safety Research, 2016; 56, 105-109. doi:10.1016/j.jsr.2015.11.002.

23. Web-based Injury Statistics Query and Reporting System 2015. Centers for Disease Control and Prevention [on-line]. Available at http://www.cdc.gov/ injury/wisqars/ Accessed December 12, 2015.

24. Oliver D, Healey F, Haines TP.Preventing falls and fall-related injuries in hospitals. Clin Geriatr Med. 2010 Nov;26(4):645-92. doi: 10.1016/j.cger.2010.06.005.

25. Quarranttey G.K. Falls and Related Injuries Based on Surveillance Data: U.S. Hospital Emergency Departments. Walden University, College of Health Sciences 2016.

26. Karataş GK, Maral I. Ankara- Gölbaşı İlçesinde Geriatrik Popülasyonda 6 Aylık Dönemde Düşme Sıklığı ve Düşme İçin Risk Faktörleri. Turkish Journal of Geriatrics 2001; 4(4): 152-158.

27. Öz FB. Bir hastane acil servisine düşme ön tanısılla başvuran 65 yaş üstü bireylerde evde düşme risk faktörlerinin belirlenmesi, Yüksek Lisans Tezi, Mersin Üniversitesi,Sağlık Bilimleri Enstitüsü, Mersin 2016.

28. Lin FR, Ferrucci L. Hearing loss and falls among older adults in the United States. Arch Intern Med. 2012;172(4):369-371.

29. Lord SR. Visual risk factors for falls in older people. Age Ageing. 2006 Sep;35 Suppl 2:ii42-ii45. 
30. Källstrand-Ericson J, Hildingh C. Visual impairment and falls: a register study. J Clin Nurs. 2009 Feb;18(3):366-72. doi: 10.1111/j.1365-2702.2008.02516.x.

31. Criter RE, Honaker JA. Fall risk screening protocol for older hearing clinic patients. Int J Audiol. 2017 Oct;56(10):767-774. doi: 10.1080/14992027.2017.1329555. Epub 2017 May 25.

32. Morse J. Development of the Morse Fall Scale. Preventing Patient Falls. U.S. of America, First Edition, 1997.

33. Soyuer F, Soyuer A, Öztürk A. Kronik inmede düşmeyi etkileyen faktörler. Türk Serebrovasküler Hastalıklar Dergisi. 2006; 12(3): 83-87.

34. Ganz DA, Bao Y, Shekelle PG, Rubenstein LZ. Will my patient fall? JAMA. 2007; 297(1):77-86.

35. Huang AR, Mallet L, Rochefort CM, Eguale T, Buckeridge DL, Tamblyn R. Medication-related falls in the elderly: causative factors and preventive strategies. Drugs Aging. 2012 May 1;29(5):359-76. doi: 10.2165/11599460-000000000-00000.

36. Titler MG, Shever LL, Kanak MF, Picone DM \&Qin R. Factors associated with falls during hospitalization in an older adult population. Research and Theory for Nursing Practice.2011; 25:127-148.

37. Gauterio DP, Zortea B, Costa SantosSS, da Silva Tarouco B, Lopes MJ, Jo ao Fonseca C. Risk Factorsfor new accidental falls in elderly patients at traumatology ambulatory center. Imprenta Universidad de Antioquia. 2015; 33:35-43.

38. Hou WH, Kang CM, Ho MH, Kuo JM, Chen HL, Chang WY. Evaluation of an inpatient fall risk screening tool to identify the most critical fall risk factors in inpatients. J Clin Nurs. 2017; 26(5-6):698-706.

39. Nogal L, Gonzales L, Ramirez G, Casado R. Characteristics of Falls of Neurological Cause in the Elderly. Revista De Neurologia. 2008; 46(9); s. 513-516.

40. Salameh F, Cassuto N, Oliven A. A simplified fall-risk assessment tool for patients hospitalized in medical wards. Isr Med Assoc J. 2008; 10(2):125-129. 